\title{
The effects of EPA and DHA enriched fish oil on nutritional and immunological markers of treatment naïve breast cancer patients: a randomized double-blind controlled trial
}

Elemárcia Martins da Silva Paixão ${ }^{*}$, Ana Carolina de M. Oliveira', Nathalia Pizato ${ }^{1}$, Maria Imaculada Muniz-Junqueira ${ }^{2}$, Kelly G. Magalhães ${ }^{3}$, Eduardo Yoshio Nakano ${ }^{4}$ and Marina K. Ito ${ }^{1}$

\begin{abstract}
Background: We evaluated the effects of eicosapentaenoic (EPA) and docosahexaenoic (DHA) acids enriched fish oil (FO) on nutritional and immunological parameters of treatment naïve breast cancer patients.

Methods: In a randomized double blind controlled trial, the FO group (FG) patients were supplemented with $2 \mathrm{~g} /$ day of FO concentrate containing $1.8 \mathrm{~g}$ of $\mathrm{n}-3$ fatty acids during 30 days. The placebo group (PG) received $2 \mathrm{~g} /$ day of mineral oil. At baseline and after the intervention, plasma levels of $\mathrm{n}-3$ fatty acids, dietary intake, weight, body composition, biochemical and immunological markers were assessed.
\end{abstract}

Results: At the end of the intervention period, no between group differences were observed regarding anthropometric parameters. There was a significant increase in the plasma phospholipid EPA $(p=0.004)$, DHA $(p=0.007)$ of the FG patients. In FG patients the percentages of peripheral blood $\mathrm{CD}^{+} \mathrm{T}$ lymphocytes and serum high sensitivity C-reactive protein (hsCRP) levels were maintained while in PG patients there was a significant increase in hsCRP ( $p=0.024)$. We also observed a significant reduction in the percentage of $C D 4^{+} T$ lymphocytes in the peripheral blood $(p=0.042)$ of PG patients. No changes in serum proinflammatory cytokine and prostaglandin $\mathrm{E}_{2}$ levels were observed.

Conclusions: Supplementation of newly diagnosed breast cancer patients with EPA and DHA led to a significant change in the composition of plasma fatty acids, maintained the level of $\mathrm{CD}^{+} \mathrm{T}$ cells and serum levels of hsCRP, suggestive of a beneficial effect on the immune system and less active inflammatory response.

Trial registration: Brazilian Clinical Trials Registry (REBEC): RBR-2b2hqh. Registered 29 April 2013, retrospectively registered.

Keywords: Breast cancer, N-3 fatty acids, Fish oil, Immunonutrition, Cytokines, Eicosapentaenoic acid (EPA)

\footnotetext{
* Correspondence: e.paixao@yahoo.com.br

${ }^{1}$ Post Graduate Program in Human Nutrition, University of Brasília, Brasilia,

Federal District 70910-900, Brazil

Full list of author information is available at the end of the article
} 


\section{Introduction}

Cell-mediated immune response (IR) plays an important role in cancer immunoediting. $\mathrm{CD}^{+}$and $\mathrm{CD}^{+} \mathrm{T}$ cells are the main lymphocytes involved in cell-mediated immunity. It is established that an effective anti-tumor IR requires the participation of both types of $\mathrm{T}$ lymphocytes cells, since the $\mathrm{CD}^{+} \mathrm{T}$ cells are critical for the generation of tumor-specific cytotoxic T cells as well as memory $\mathrm{T}$ cells expansion [1]. Fatty acids are modulators of lymphocyte functions. Both the type of fatty acids present in the diet and their serum levels may influence lymphocyte proliferation, cytokine production and $\mathrm{T}$ lymphocyte migration [2, 3].

Breast cancer patients have altered cell-mediated IR compared to healthy controls. In newly diagnosed patients, low peripheral blood $\mathrm{CD}^{+}$cell counts have been observed [4, 5]. Moreover, results contrary to the above [6] or those who showed no difference between patients and controls [7] have also been published. Furthermore, even in the early stages, breast cancer patients have increased serum levels of prostaglandin $\mathrm{E}_{2}\left(\mathrm{PGE}_{2}\right)$ [8] and proinflammatory cytokines such as tumor necrosis factor alpha (TNF- $\alpha$ ), interleukin (IL)-1 $\beta$ and IL-6 [9]. Elevated serum levels of $\mathrm{C}$-reactive protein (CRP) at the time of diagnosis were observed and associated with shorter disease-free survival and overall survival of breast cancer patients [10].

Diagnosis of cancer can motivate patients to alter their dietary habits on its own. Nutritional supplement intake such as fish oil, which is the principal source of n-3 fatty acids eicosapentaenoic acid (EPA) and docosahexaenoic acid (DHA), is highly prevalent among breast cancer patients [11]. The benefit of n-3 fatty acid intake on breast cancer incidence has been reported in a recent systematic review of prospective cohort studies, that suggested a dose response relationship of $5 \%$ lower risk for each $0.1 \mathrm{~g} /$ day increment of marine n-3 fatty acid intake [12]. For those already with the disease, specific human intervention studies are limited and the results have been variable [13-15]. In metastatic breast cancer patients, oral supplementation with DHA during chemotherapy potentially improved patient survival [13] and in patients under chemo or radiotherapy for other types of cancer, the supplementation with EPA and DHA increased body weight [16] and reduced serum CRP [17], proinflammatory cytokines and $\mathrm{PGE}_{2}$ levels [14, 16, 17]. However, there is a gap of knowledge on the potential benefit of n-3 fatty acid intake for breast cancer patients at early stages of treatment.

Thus, the aim of this study was to investigate whether supplementation with EPA and DHA, immediately following the diagnosis of breast cancer but prior to treatment, would have a positive impact on patient's nutritional and selected immune parameters.

\section{Materials \& methods Study population}

Breast cancer patients attending the University Hospital of Brasilia and the Base Hospital of the Federal District were invited to participate. Inclusion criteria were treatment-naïve patients between 18 and 70 years of age, with mammographic image classification $4 \mathrm{C}$ or higher according to Breast Imaging-Reporting and Data System (BI-RADS), and with surgery as primary treatment option. BI-RADS 4C denotes "finding of moderate concern of being cancer" and patients in this category are advised to perform biopsy exams. Exclusion criteria were patients with metastatic or recurrent disease, comorbidity or other disease that prevented the use of fish oil or affected the blood parameters being studied, pacemaker users and those unable to be weighted or with edema. All patients signed an informed consent before entering the study.

\section{Study design}

A randomized, controlled, double-blind study was conducted between the period of February 2012 and March 2013. The study was carried out in compliance with Good Clinical Practice and the Consolidated Standards for Reporting of Trials (CONSORT) statement. The study protocol was approved by the Human Research Ethics Committees of the University of Brasilia and of the Federal District Health Secretariat. The Brazilian Registry of Clinical Trials (ReBEC) is one of the primary registry site of the WHO International Clinical Trials and the study was registered as RBR-2B2hqh. The randomization was done beforehand and performed by manual raffling the blocks of ten sequential numbers with five chances of being raffled to one of the two groups. A laboratory technician not involved in the research performed the randomization, assigned fish oil group (FG) or placebo group (PG) to the sequential numbers and kept the randomized sequence secret to the project team members and patients until the last patient's data collection were finished. Patients were randomized only after positive biopsy confirmation for malignancy. The same technician provided the blinded supplement (which was identified only with the sequential numbers) to the research team. The supplements were supplied in white plastic bottles containing 30 capsules (sufficient for 15 days). Patients entering the study were assigned to the sequential identification number. The intervention lasted 30 days, immediately following the diagnosis and before the surgical procedure. Thirty days was the mean time needed for patients to go through pre-surgery exams. Patients were scheduled to return in the middle of the intervention period, when the second supplement bottle was given. At the final visit, patients were asked to return any unused capsules. 
Twelve hours fasted blood samples were collected for biochemical and immunological analyses at baseline and at the end of the intervention period. For the evaluation of nutritional status, body weight, height and body composition analyses were performed. Dietary intake was evaluated by 24-h recall method, two at baseline and two at the end of intervention.

\section{Fish oil supplements}

Bulk fish oil concentrate (MaxOmega 46/38 EE , Equateq Ltd., United Kingdom) and mineral oil were purchased and encapsulated (Relthy Laboratories Ltd., Brazil) in $1 \mathrm{~g}$ gel capsules. FG patients were asked to ingest $2 \mathrm{~g}$ of fish oil concentrate (2 capsules) daily for 30 days, at lunch and dinner times. Each gram of fish oil concentrate contained $470 \mathrm{mg}$ of EPA, $390 \mathrm{mg}$ of DHA plus $18: 3 \mathrm{n} 3$ acid, in the form of ethyl esters, with a total of $1.81 \mathrm{~g}$ of $\mathrm{n}-3$ fatty acids per day, according to the manufacturer's information and confirmed in our lab. The fish oil capsules also contained $0.32 \%(w / w)$ of vitamin E ( $\alpha$-tocopherol) as antioxidant. Placebo group patients were given $2 \mathrm{~g}$ per day of mineral oil of the same color and smell of the fish oil supplement, divided in 2 capsules of $1 \mathrm{~g}$ each. In our study, rather than masking the typical odor of fish oil, the plastic bottles for mineral oil capsules were previously treated with fish oil capsules. This procedure added subtle fish oil smell to the bottles of mineral oil, thus, all patients thought they were receiving fish oil capsules.

Compliance was promoted by regular telephone contact with the patients and was monitored by counting the returned capsules at 15 th and 30th day visits. Plasma phospholipid fatty acid profile before and at the end of the intervention was also analyzed for compliance evaluation.

\section{Nutritional status and dietary intake}

Weight and height were measured in a Toledo digital scale and a metal stadiometer attached to the scale, using standard procedure. Body mass index (BMI) was calculated and classified according to the World Health Organization cutoff values [18].

The bioelectrical impedance analysis was performed with BIA Quantum II instrument (RJL Systems ${ }^{\odot}$ ) according to the standardized procedure. The phase angle (PA) was obtained from the arc tangent relationship of reactance/ resistance $\times 180 / \pi[19]$.

Dietary intake was assessed by 24-h recall using the method of multiple passes and nutrient composition was calculated with NutWin (1.5.2.51 version) software. NutWin uses the USDA food composition database for nutrient calculation.

\section{Blood analysis}

Blood samples were obtained for biochemical (serum) and immunological analysis (plasma). Biochemical analysis included serum glucose, total cholesterol, high- and lowdensity lipoprotein cholesterol and triglycerides (Labtest ${ }^{\circ}$ ), complete blood count (CELL-DYN 3500 system), albumin and high sensitivity C-reactive protein (hsCRP) by immunonephelometry $\left(\right.$ Siemens $\left.{ }^{\oplus}\right)$. Immunological parameters evaluated were peripheral blood mononuclear $\mathrm{CD}^{+}$e $\mathrm{CD}^{+}$lymphocyte cell counts, plasma cytokines and $\mathrm{PGE}_{2}$. Plasma phospholipid fatty acid profile was also analyzed as a marker of compliance.

\section{Flow-cytometric analysis}

The peripheral blood mononuclear cells (PBMC) were obtained by density gradient centrifugation with Histopaque $^{\bullet}$ - 1077 (Sigma-Aldrich). Lymphocytes were suspended in phosphate buffered saline at a concentration of $5 \times 10^{5}$ cells/ well. $\mathrm{CD}^{+}$and $\mathrm{CD}^{+}$cells were counted with surface marker PE mouse anti-human CD4 and CD8 (BD Biosciences, USA). The analysis was performed in a FACSCalibur flow cytometer equipped with CellQuest software (BD Biosciences, USA). Twenty thousand events were acquired from each sample and the results were analyzed using FlowJo software, version 10.0 (Treestar, Inc. USA).

\section{Proinflammatory cytokines and prostaglandin $E_{2}$} Plasma IL-6, IL-1 $\beta$ and TNF- $\alpha$ cytokines were quantified by the ELISA method (Bioscience, San Diego, USA). Prostaglandin $E_{2}$ metabolites were quantified by competition ELISA method using the Prostaglandin E Metabolite EIA kit (Cayman Chemical Company, USA) according to the manufacturer's instructions.

\section{Phospholipid fatty acid profile}

Plasma lipid was extracted according to Folch et al. [20] and phospholipids were separated by thin layer chromatography with solvent system hexane: diethyl ether: acetic acid (80:20:2 v/v/v) [21]. Phospholipid fatty acids were esterified by acid methylation [21] and analyzed by gas chromatography (GC) (Shimadzu, 17A model), using SP2560 column (Supelco, Bellefonte, PA, USA). Fatty acids were identified using external standards (Sigma ${ }^{\circ}$ ) and the results were expressed as percentage of fatty acid in relation to the total area of the fatty acids.

\section{Statistical analysis}

Primary end points of this study (nutritional status/ body weight) have not been reported in breast cancer patients receiving $n-3$ fatty acids prior to treatment. The sample size calculation was performed on the basis of Bougnoux et al. study [13], which assessed the effect of DHA in breast cancer patients during chemotherapy (that study 
found objective response rate to treatment in $44 \%$ of patients). Assuming a hypothesis that no more than $5 \%$ of placebo group would present a positive response (in immunological or nutritional parameter), we estimated that a minimum sample of 16 subjects in each group would allow the detection of differences due to the effect of $n-3$ use, with a $80 \%$ power and $5 \%$ significance level.

Descriptive statistics were presented as percentages, means and standard deviations or median (upper and lower quartiles). Baseline results were analyzed using the chi-square test for categorical variables and Mann Whitney test for continuous variables. To check for intra group differences, the Wilcoxon test was used. Differences between groups were verified by a two-way repeated measures ANOVA for ordinal data with group (fish oil and placebo) as between subject factor and time as within subject factor [22]. All tests were two-tailed and the significance level was set at $p<0.05$. Analyses were performed using $\mathrm{R}$ free software.

\section{Results}

Study population

One hundred and eight patients were invited to participate in the study (Fig. 1). Of these, 77 (71\%) accepted the invitation, but 32 patients were excluded due to: loss of contact for the baseline visit $(n=6)$, surgery scheduled to date shorter than 30 days $(n=16)$, change in clinical treatment $(n=3)$ and negative biopsy $(n=7)$. Thus, 45 patients were randomized. Of the randomized patients, eight of them discontinued the study due to supplement intolerance $(n=2)$ and to change to neoadjuvant chemotherapy as primary treatment $(n=6)$. Thirty seven patients completed the study, of whom 18 were supplemented with fish oil and 19 with placebo.

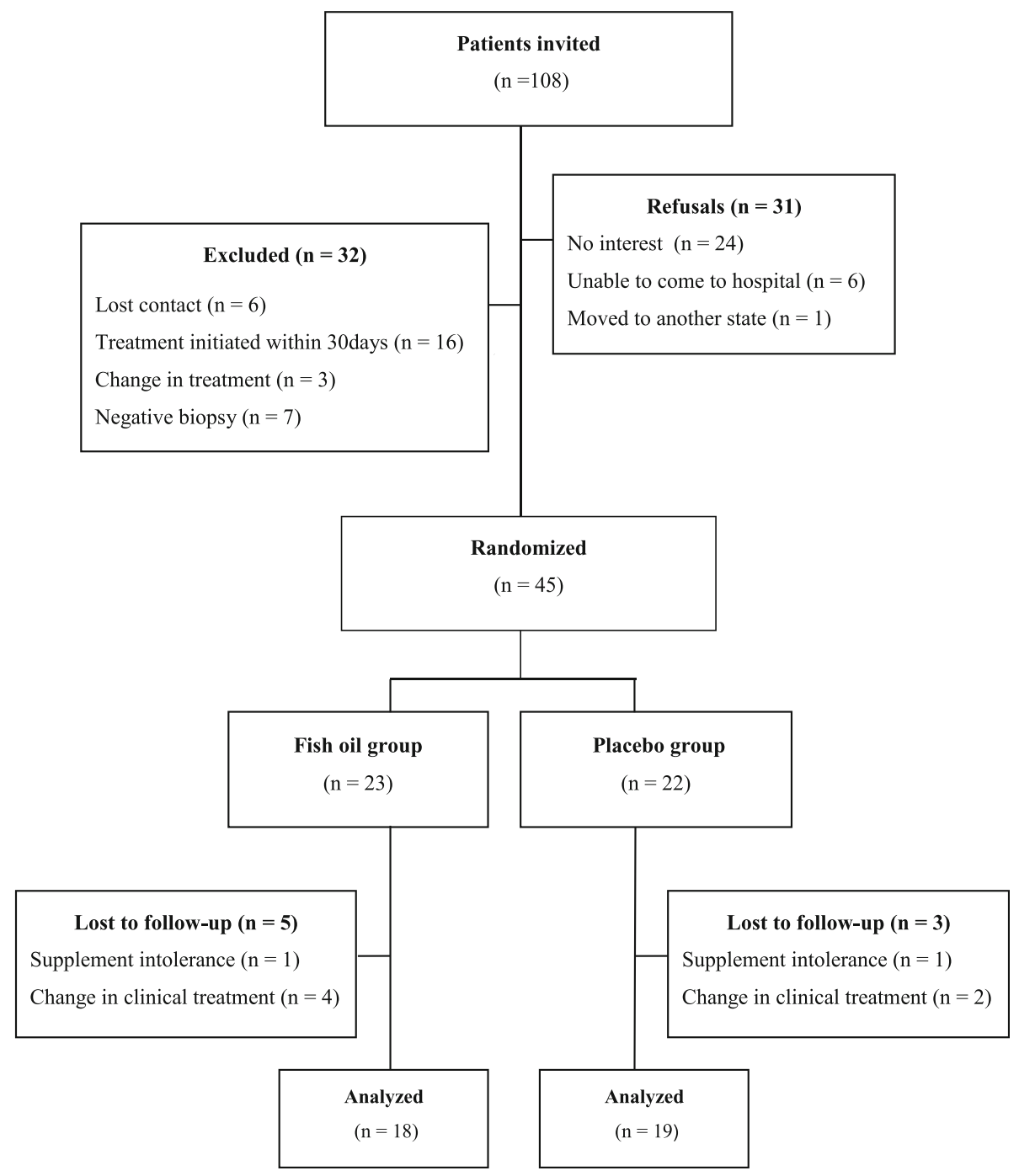

Fig. 1 CONSORT flow chart 


\section{Baseline characteristics}

The socio-demographic and clinic-pathological characteristics of patients at baseline are shown in Table 1 . Most of the patients had infiltrating ductal carcinoma (62\%), clinical staging 0/ I/ II (56\%), estrogen receptor $+(\mathrm{ER}+)(72 \%)$, progesterone receptor $+(\mathrm{PR}+)(59 \%)$ and negative for human epidermal growth factor receptor 2 (HER2) (56\%). There was no significant difference between the FG and PG groups with respect to these variables.

Table 1 Socio-demographic and clinicopathological characteristics of patients randomized according to the study group

\begin{tabular}{|c|c|c|c|}
\hline & \multicolumn{2}{|l|}{ Groups } & \multirow[t]{2}{*}{$p^{a}$} \\
\hline & $\begin{array}{l}\text { Fish oil } \\
(n=18)\end{array}$ & $\begin{array}{l}\text { Placebo } \\
(n=19)\end{array}$ & \\
\hline Age (years) ${ }^{b}$ & $48.6 \pm 9.0$ & $53.4 \pm 7.5$ & 0.107 \\
\hline Education level (years) ${ }^{b}$ & $7.2 \pm 3.9$ & $9.1 \pm 4.0$ & 0.227 \\
\hline \multicolumn{4}{|l|}{ Menopause \% (n) } \\
\hline No & $50.0(9)$ & $26.3(5)$ & \multirow[t]{2}{*}{0.138} \\
\hline Yes & $50.0(9)$ & $73.7(14)$ & \\
\hline \multicolumn{4}{|l|}{ Histological type \% (n) } \\
\hline Ductal carcinoma in situ (DCIS) & $22.2(4)$ & $10.5(2)$ & \multirow[t]{4}{*}{0.756} \\
\hline Infiltrating ductal carcinoma (IDC) & $72.2(13)$ & $78.9(15)$ & \\
\hline$I D C+D C I S$ & $5.6(1)$ & $5.3(1)$ & \\
\hline No information & - & $5.3(1)$ & \\
\hline \multicolumn{4}{|l|}{ TNM classification \% (n) } \\
\hline Tumor in situ & $16.7(3)$ & - & - \\
\hline । & $16.7(3)$ & $5.3(1)$ & \multirow[t]{4}{*}{0.212} \\
\hline$\|$ & $38.9(7)$ & $47.4(9)$ & \\
\hline III & $27.8(5)$ & $42.1(8)$ & \\
\hline No information & - & $5.3(1)$ & \\
\hline \multicolumn{4}{|l|}{ Estrogen receptor (ER) \% (n) } \\
\hline ER+ & $77.8(14)$ & $73.7(14)$ & \multirow[t]{3}{*}{1.000} \\
\hline ER- & $16.7(3)$ & $15.8(3)$ & \\
\hline No information & $5.6(1)$ & $10.8(2)$ & \\
\hline \multicolumn{4}{|l|}{ Progesterone receptor (PR) \% (n) } \\
\hline $\mathrm{PR}+$ & $66.7(12)$ & $57.9(11)$ & \multirow[t]{3}{*}{1.000} \\
\hline PR- & $27.8(5)$ & $31.6(6)$ & \\
\hline No information & $5.6(1)$ & $10.5(2)$ & \\
\hline \multicolumn{4}{|c|}{ Human epidermal growth factor receptor 2 (HER2) \% (n) } \\
\hline HER2+ & $33.3(6)$ & $26.3(5)$ & \multirow[t]{3}{*}{1.000} \\
\hline HER2- & $61.1(11)$ & $63.2(12)$ & \\
\hline No information & $5.6(1)$ & $10.5(2)$ & \\
\hline
\end{tabular}

TNM Tumor, node, metastasis

${ }^{a}$ Mann-Whitney test for age and education level and chi-square for the other variables

${ }^{\mathrm{b}}$ Mean \pm standard deviation
According to the BMI classification, the majority of the patients had excess weight, $43 \%$ being classified as overweight and $30 \%$ as obese. No between group differences existed in the anthropometric parameters and intake variables. The daily consumption of EPA and DHA was low in both groups, with medians of $0.005 \mathrm{~g} /$ day of EPA and $0.020 \mathrm{~g} /$ day of DHA, among FG patients and $0.005 \mathrm{~g} /$ day and $0.025 \mathrm{~g} /$ day, respectively, in the PG.

The percentage of baseline plasma phospholipid EPA were $0.4 \%$ and $0.3 \%$ in FG and PG, respectively; while DHA were $2.5 \%$ and $3.1 \%$, with no group differences. The FG had significantly lower percentage of oleic acid $(p=0.027)$ and a higher ratio of 18.0/18.1 $(p=0.022)$ when compared with PG. The percentage of other fatty acids was similar between the groups.

There was no significant difference between the groups regarding the baseline percentage and ratio of PBMN $\mathrm{CD}^{+}$and $\mathrm{CD}^{+}$lymphocytes, serum levels of proinflammatory cytokines (TNF- $\alpha$, IL- 6 and IL-1 $\beta$ ), PGE metabolites and hsCRP. With the exception of monocytes, blood count and serum biochemical parameters were similar between FG and PG.

\section{Tolerability and compliance}

Among the patients who completed the study, 55\% and $47 \%$ of the FG and PG patients, respectively, reported side effects such as dizziness, nausea, frequent belching, increased bowel frequency, heartburn and gastric fullness. However, no between group differences was observed for the presence of symptoms $(p=0.616)$. Despite the reported side effects, $92 \%$ and $93 \%$ of the prescribed capsules were consumed in the FG and PG, respectively, which was considered as good supplement compliance.

\section{Intervention effects}

The effects of the intervention on nutritional status and dietary intake are shown in Table 2. At the end of the intervention period, the FG patients presented significant gain of fat mass $(p=0.029)$, but no difference was observed between the groups regarding this and other anthropometric parameters analyzed. There was no intra group difference in the macronutrient intake, both in the PG and FG patients. However, there was a between group difference in energy $(p=0.038)$ and protein $(p=0.010)$ ingestion being higher in PG. The FG group intake of monounsaturated, palmitic, stearic and oleic fatty acids reduced significantly, however, with no between group differences. The dietary EPA, DHA and total n-3 fatty acids showed no intra or between group differences at the end of intervention period (Table 2).

Significant increase in plasma total $\mathrm{n}-3$ fatty acids $(p=0.004)$ and decrease in $\mathrm{n}-6: \mathrm{n}-3$ ratio $(p=0.002)$ 
Table 2 Nutritional status and dietary intake at baseline and at the end of the study

\begin{tabular}{|c|c|c|c|c|c|c|c|c|c|c|c|}
\hline & \multicolumn{4}{|c|}{ Fish oil group $(n=18)$} & \multirow[t]{3}{*}{$p^{a}$} & \multicolumn{4}{|c|}{ Placebo group $(\mathrm{n}=19)$} & \multirow[t]{3}{*}{$p^{a}$} & \multirow[t]{3}{*}{$P^{b}$} \\
\hline & \multicolumn{2}{|c|}{ Initial } & \multicolumn{2}{|l|}{ Final } & & \multicolumn{2}{|l|}{ Initial } & \multicolumn{2}{|l|}{ Final } & & \\
\hline & Median & IQR & Median & IQR & & Median & IQR & Median & IQR & & \\
\hline \multicolumn{12}{|l|}{ Nutritional status } \\
\hline Weight (kg) & 67.3 & $62.0-74.1$ & 67.5 & $62.8-77.6$ & 0.078 & 66.6 & $57.7-73.2$ & 67.5 & $57.5-71.7$ & 0.776 & 0.079 \\
\hline BMI $\left(\mathrm{kg} / \mathrm{m}^{2}\right)$ & 27.0 & $23.7-32.0$ & 27.1 & $23.6-32.5$ & 0.078 & 26.6 & $24.9-30.2$ & 26.3 & $24.8-29.6$ & 0.723 & 0.101 \\
\hline Lean body mass (kg) & 41.5 & $39.6-45.7$ & 41.0 & $45.0-43.2$ & 0.170 & 40.5 & $34.8-44.0$ & 40.4 & $34.8-43.8$ & 0.660 & 0.406 \\
\hline Fat mass (kg) & 26.3 & $19.5-33.0$ & 26.8 & $21.9-34.6$ & 0.029 & 26.5 & $21.6-30.2$ & 24.3 & $22.1-29.8$ & 0.977 & 0.101 \\
\hline$\%$ Body fat & 37.7 & $28.1-44.9$ & 38.1 & $33.2-46.0$ & 0.149 & 38.9 & $37.0-43.8$ & 39.4 & $35.9-42.0$ & 0.820 & 0.298 \\
\hline SPA & -0.6 & $-1.2--0.2$ & -0.7 & $-1.1-0.1$ & 0.513 & -1.2 & $-1.6--0.6$ & -1.1 & $-1.63--0.7$ & 0.394 & 0.492 \\
\hline \multicolumn{12}{|l|}{ Dietary intake } \\
\hline Energy (kcal) & 1451 & $1052-1755$ & 1226 & $1011-1629$ & 0.124 & 1162 & $991-1500$ & 1289 & $1186-1480$ & 0.520 & 0.038 \\
\hline $\mathrm{Kcal} / \mathrm{kg}$ & 21 & $16-27$ & 17 & $14-24$ & 0.173 & 20 & $14-22$ & 20 & $16-23$ & 0.877 & 0.259 \\
\hline Carbohydrates (g) & 172 & $128-260$ & 155 & $118-235$ & 0.148 & 147 & 133-186 & 171 & $118-226$ & 0.557 & 0.200 \\
\hline Protein (g) & 64 & $48-80$ & 47 & $42-60$ & 0.124 & 51 & $44-68$ & 62 & $47-81$ & 0.184 & 0.010 \\
\hline Lipids (g) & 45 & $34-66$ & 42 & $37-51$ & 0.124 & 42 & $33-53$ & 38 & $27-53$ & 0.546 & 0.686 \\
\hline \multicolumn{12}{|l|}{ Fat acids (g) } \\
\hline Saturated & 11.1 & $7.6-15.7$ & 9.4 & $8.1-13.5$ & 0.163 & 8.9 & $7.5-13.4$ & 9.5 & $6.7-13.5$ & 0.936 & 0.536 \\
\hline Monounsaturated & 11.6 & $9.1-19.3$ & 10.9 & $7.5-13.7$ & 0.039 & 10.5 & $8.6-14.7$ & 9.4 & $6.9-15.0$ & 0.673 & 0.747 \\
\hline Polyunsaturated & 9.4 & $7.4-11.5$ & 8.1 & $7.2-10.6$ & 0.163 & 9.0 & $7.1-10.6$ & 8.0 & $6.5-10.0$ & 0.376 & 0.752 \\
\hline $16: 0$ & 6.3 & $4.6-9.7$ & 5.3 & $3.9-7.0$ & 0.013 & 5.3 & $4.5-7.6$ & 5.2 & $3.9-7.5$ & 0.809 & 0.449 \\
\hline $18 ; 0$ & 2.6 & $1.9-4.6$ & 2.4 & $1.5-3.4$ & 0.019 & 2.1 & $1.8-3.3$ & 2.2 & $1.6-3.8$ & 1.000 & 0.489 \\
\hline $18: 1 n-9$ & 10.7 & $8.4-17.8$ & 10.1 & $7.0-12.7$ & 0.049 & 9.5 & $7.7-13.6$ & 8.5 & $6.3-14.6$ & 0.629 & 0.838 \\
\hline $18: 2 n-6$ & 7.8 & $6.9-9.9$ & 7.0 & $6.3-9.7$ & 0.177 & 7.9 & $6.1-9.3$ & 7.0 & $5.6-8.5$ & 0.243 & 0.842 \\
\hline $18: 3 n-3$ & 0.9 & $0.7-1.1$ & 0.8 & $0.7-1.1$ & 0.981 & 0.8 & $0.6-0.8$ & 0.8 & $0.5-0.9$ & 0.794 & 0.776 \\
\hline $20: 4 n-6$ & 0.10 & $0.47-0.17$ & 0.07 & $0.54-0.11$ & 0.163 & 0.09 & $0.05-0.12$ & 0.09 & $0.06-0.19$ & 0.162 & 0.165 \\
\hline $20: 5 n-3(E P A)$ & 0.005 & $0.000-0.007$ & 0.005 & $0.000-0.010$ & 0.633 & 0.005 & $0.000-0.010$ & 0.005 & $0.000-0.015$ & 0.395 & 0.334 \\
\hline 22:6n-3 (DHA) & 0.020 & $0.002-0.052$ & 0.020 & $0.005-0.032$ & 0.162 & 0.025 & $0.010-0.030$ & 0.015 & $0.000-0.065$ & 0.139 & 0.295 \\
\hline Total n-3 & 1.0 & $0.7-1.3$ & 0.8 & $0.8-11$ & 0.850 & 0.8 & $0.6-1.1$ & 0.8 & $0.6-1.0$ & 0.831 & 0.711 \\
\hline Total n-6 & 8.3 & $7.1-10.2$ & 7.2 & $6.4-9.7$ & 0.201 & 8.0 & $6.2-9.4$ & 7.0 & $5.2-8.4$ & 0.163 & 0.850 \\
\hline$n-6 / n-3$ ratio & 8.3 & $5.8-9.7$ & 7.8 & $7.4-8.8$ & 0.723 & 8.3 & $7.3-10.1$ & 7.2 & $6.7-10.5$ & 0.381 & 0.175 \\
\hline 18:0/18:1 ratio & 0.2 & $0.2-0.2$ & 0.2 & $0.2-0.2$ & 0.554 & 0.2 & $0.2-0.2$ & 0.2 & $0.2-0.2$ & 0.469 & 0.387 \\
\hline
\end{tabular}

IQR Interquartile range, BMI Body mass index, SPA Standardized phase angle, EPA Eicosapentaenoic acid, DHA Docosahexaenoic acid

${ }^{a}$ Intragroup differences according to Wilcoxon test

${ }^{b}$ Interaction test of a two-way repeated measures ANOVA for ordinal data to verify the significance of differences between fish oil and mineral oil groups

was seen in FG patients, with a significant between group differences ( $p=0.005$ and $p=0.012$, respectively) (Table 3).

Regarding the acute phase immunological response, no significant change was observed in the FG (initial median 0.1 [IQR 0.1-0.5], final median 0.3 [IQR 0.0$0.7], p=0.510$ ) while in PG patients there was a significant increase in hsCRP (initial median 0.1 [IQR 0.0-0.2], final median 0.2 [IQR 0.1-0.3], $p=0.024$ ). While hsCRP remained stable in patients supplemented with n-3 fatty acids, the PG patients had a more pronounced increase in serum hsCRP levels, with a non-significant between group difference (FG $\Delta \%=-5.9$ [-35.4-74.12], PG $\Delta \%=17.2[-0.16-91.99] p=0.059)$ (Fig. 2). No significant changes in serum TNF- $\alpha$, IL-1 $\beta$, IL- 6 cytokines were observed.

We observed a significant reduction in the percentage of $\mathrm{CD}^{+} \mathrm{T}$ lymphocytes in the peripheral blood of PG patients (initial median 57.2 [IQR 47.7-71.8], final median 52.7 [IQR 42.3-57.9], $p=0.042$ ) and no change in the percentage of $\mathrm{CD}^{+}$cells. In the FG, no change in the percentages of $\mathrm{CD}_{4}^{+}$and $\mathrm{CD} 8^{+} \mathrm{T}$ cells and $\mathrm{CD} 4^{+} /$ $\mathrm{CD}^{+}$ratio occurred. No between group effects of treatment $(\Delta \%)$ were observed for these parameters (Fig. 3). 
Table 3 Blood fatty acids profile at baseline and at the end of the study in both groups

\begin{tabular}{|c|c|c|c|c|c|c|c|c|c|c|c|}
\hline & \multicolumn{4}{|c|}{ Fish oil group $(n=18)$} & \multirow[t]{3}{*}{$p^{a}$} & \multicolumn{4}{|c|}{ Placebo group $(n=19)$} & \multirow[t]{3}{*}{$p^{a}$} & \multirow[t]{3}{*}{$p^{b}$} \\
\hline & \multicolumn{2}{|l|}{ Initial } & \multicolumn{2}{|l|}{ Final } & & \multicolumn{2}{|l|}{ Initial } & \multicolumn{2}{|l|}{ Final } & & \\
\hline & Median & IQR & Median & IQR & & Median & IQR & Median & IQR & & \\
\hline \multicolumn{12}{|l|}{ Fatty acids } \\
\hline Saturated & 58.7 & $50.4-63.5$ & 58.4 & $50.6-64.4$ & 0.863 & 52.2 & $49.1-60.7$ & 55.2 & $48.9-59.1$ & 0.601 & 0.857 \\
\hline Monounsaturated & 10.1 & $9.0-11.3$ & 9.8 & $8.5-10.9$ & 0.130 & 9.8 & $9.2-12.2$ & 10.6 & $8.5-11.9$ & 0.809 & 0.326 \\
\hline Polyunsaturated & 27.4 & 21.9-33.3 & 27.9 & $25.0-38.0$ & 0.113 & 36.1 & $25.4-37.7$ & 35.2 & $28.2-38.8$ & 0.376 & 0.795 \\
\hline $16: 0$ & 29.9 & $24.6-35.1$ & 30.4 & $23.6-34.7$ & 0.356 & 25.0 & $22.1-31.3$ & 25.7 & $22.7-29.6$ & 0.717 & 0.824 \\
\hline $18: 0$ & 16.8 & $15.3-17.4$ & 17.4 & $15.7-18.6$ & 0.356 & 15.3 & $13.7-18.5$ & 15.9 & $12.9-17.1$ & 0.841 & 0.409 \\
\hline $18: 1 n-9$ & 4.3 & $3.5-5.2$ & 4.4 & $3.7-5.8$ & 0.943 & 5.2 & $4.5-6.5$ & 5.1 & $4.4-6.5$ & 0.629 & 0.525 \\
\hline $20: 4 n-6$ & 8.8 & $7.3-10.9$ & 8.2 & $6.0-10.2$ & 0.124 & 10.0 & $7.9-14.0$ & 11.1 & $8.5-12.6$ & 0.984 & 0.284 \\
\hline $20: 5 n-3$ (EPA) & 0.4 & $0.1-0.8$ & 1.5 & $0.9-2.1$ & 0.004 & 0.3 & $0.0-0.8$ & 0.5 & $0.0-1.2$ & 0.293 & 0.034 \\
\hline 22:6n-3 (DHA) & 2.5 & $1.9-3.6$ & 4.6 & $3.4-6.2$ & 0.007 & 3.1 & $2.1-5.0$ & 3.8 & $2.0-4.9$ & 0.904 & 0.000 \\
\hline Total n-3 & 3.3 & $2.4-4.9$ & 6.5 & $4.3-8.7$ & 0.004 & 3.7 & $2.6-5.9$ & 4.1 & $2.9-5.9$ & 0.952 & 0.005 \\
\hline Total n-6 & 25.0 & $19.1-30.2$ & 23.0 & $19.1-29.5$ & 0.554 & 31.6 & $22.6-32.4$ & 30.0 & $24.1-33.9$ & 0.702 & 0.246 \\
\hline$n-6: n-3$ ratio & 7.7 & $5.3-9.7$ & 3.8 & $3.0-4.7$ & 0.002 & 7.0 & $4.5-11.1$ & 6.8 & $4.4-8.8$ & 0.904 & 0.012 \\
\hline
\end{tabular}

IQR Interquartile range, EPA Eicosapentaenoic acid, DHA Docosahexaenoic acid

antragroup differences according to Wilcoxon test

${ }^{b}$ Interaction test of a two-way repeated measures ANOVA for ordinal data to verify the significance of differences between fish oil and mineral oil groups

Serum PGE metabolite levels in both groups did not change due to intervention. Serum glucose, total cholesterol and fractions, complete blood count and serum albumin showed no within or between group differences (Table 4).

\section{Discussion}

To our knowledge, this randomized controlled double blind trial is the first that investigated the effects of supplementation with n-3 fatty acids in newly diagnosed breast cancer patients, prior to treatment. In the study, the FG plasma EPA and DHA levels increased significantly after 30 days of $n-3$ supplementation. In terms of immune parameters, whereas hsCRP significantly increased and $\mathrm{CD}^{+}$reduced in the placebo group, in the $\mathrm{n}-3$ fatty acids suplemmented patients serum hsCRP and $\mathrm{CD} 4^{+}$were kept at levels similar to baseline values.

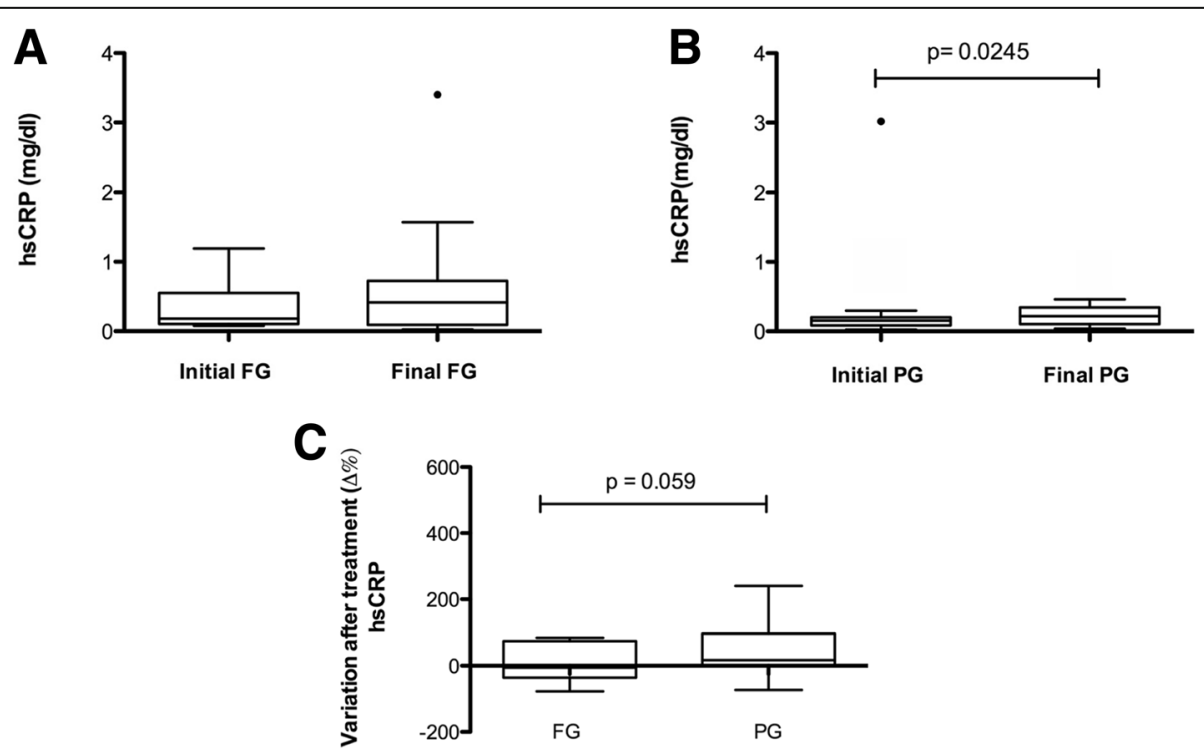

Fig. 2 Changes in high sensitivity C-reactive protein (hsCRP) according to the study groups. a Fish oil group (FG), $n=15$ (b) Placebo group (PG), $n=16$; $p$-value for the Wilcoxon test (c) Variation after treatment $(\Delta \%) n=15 ; p$ values for Mann Whitney test. Data are presented as medians, upper and lower quartiles, maximum and minimum values. (•) Outlier values indicated in the chart were excluded from the statistical analyses 

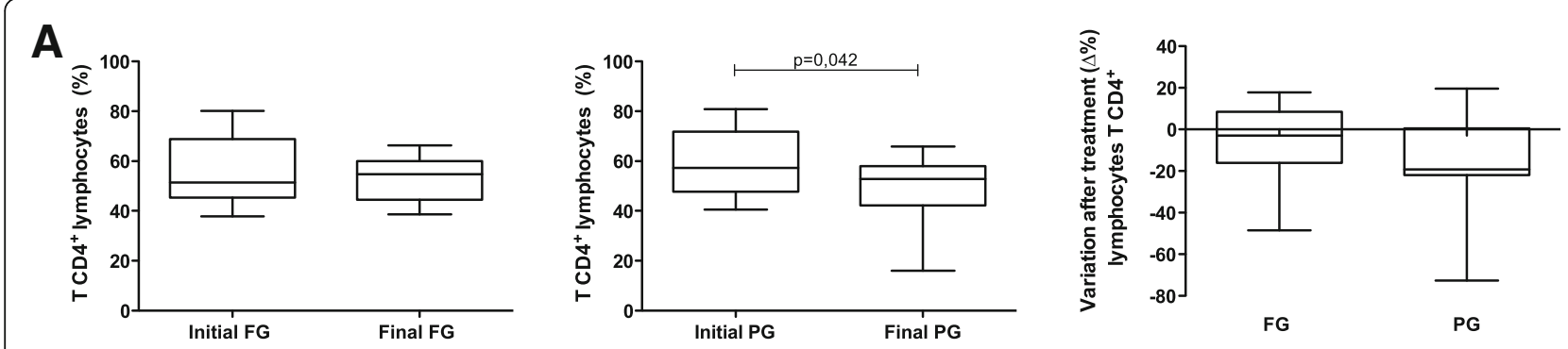

\section{B}
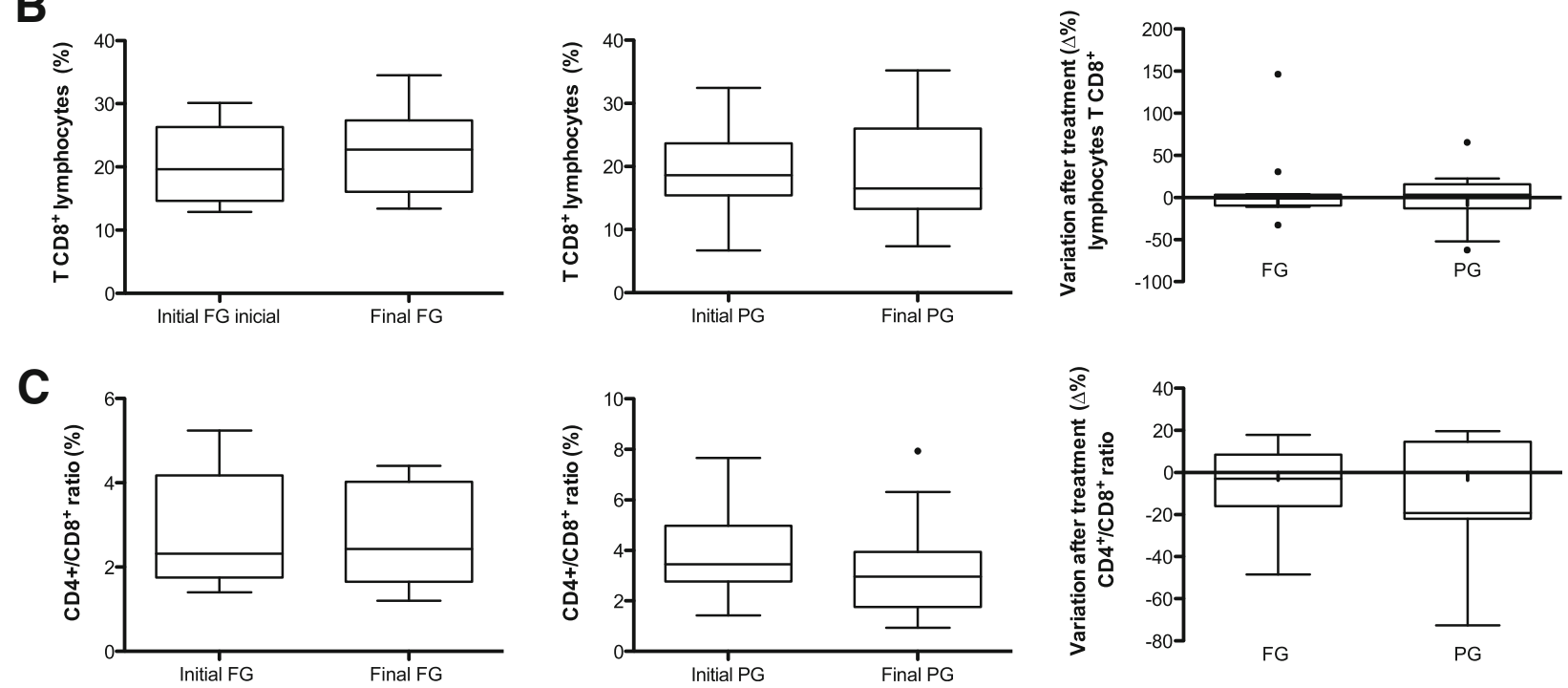

Fig. 3 Variation after treatment $(\Delta \%)$ of subpopulation of $C D 4^{+} T$ lymphocytes, $C D 8^{+}$and $C D 4^{+} / C D 8^{+}$ratio, according to the study groups. Fish oil group (FG); Placebo group (PG); (a) CD4 $4^{+}$T lymphocytes, PG $n=12$, FG $n=15 ;$ p-value for the Wilcoxon test (b) $C D 8^{+}$T Lymphocytes, PG $n=14, F G$ $n=13$ (c) $\mathrm{CD}^{+} / \mathrm{CD} 8^{+}$ratio, $\mathrm{PG} n=12$ and $\mathrm{FG} n=15$. Data are presented as medians, upper and lower quartiles, maximum and minimum values

Table 4 Biochemical parameters at baseline and at the end of the study in both groups

\begin{tabular}{|c|c|c|c|c|c|c|c|c|c|c|c|}
\hline & \multicolumn{4}{|c|}{ Fish oil group $(n=18)$} & \multirow[t]{3}{*}{$p^{a}$} & \multicolumn{4}{|c|}{ Placebo group $(n=19)$} & \multirow[t]{3}{*}{$p^{a}$} & \multirow[t]{3}{*}{$p^{b}$} \\
\hline & \multicolumn{2}{|l|}{ Initial } & \multicolumn{2}{|l|}{ Final } & & \multicolumn{2}{|l|}{ Initial } & \multicolumn{2}{|l|}{ Final } & & \\
\hline & Median & IQR & Median & IQR & & Median & IQR & Median & IQR & & \\
\hline \multicolumn{12}{|l|}{ Biochemical } \\
\hline $\mathrm{RBC}\left(\times 10^{6} / \mathrm{mm}^{3}\right)$ & 4.7 & $4.5-5.1$ & 4.7 & $4.5-4.9$ & 0.254 & 4.7 & $4.4-5.2$ & 4.7 & $4.4-4.9$ & 0.493 & 0.941 \\
\hline Hemoglobin (g/dL) & 14.0 & $12.8-15.2$ & 13.7 & $13.0-14.70$ & 0.069 & 14.0 & $13.1-14.9$ & 13.8 & $13.0-14.4$ & 0.623 & 0.426 \\
\hline Hematocrit (\%) & 41.7 & $38.3-45.7$ & 41.1 & $39.1-43.6$ & 0.139 & 42.2 & $38.6-44.0$ & 41.6 & $39.0-43.6$ & 0.877 & 0.785 \\
\hline Leucocytes $\left(\mathrm{mm}^{3}\right)$ & 6405 & $5342-7950$ & 6910 & $5105-7750$ & 0.795 & 5220 & $4150-6700$ & 5780 & $5265-6590$ & 0.653 & 0.521 \\
\hline Platelets $\left(\times 10^{3} / \mathrm{mm}^{3}\right)$ & 281.0 & 215.2-307.7 & 259.0 & $220.0-291.0$ & 0.523 & 246.0 & $193.0-282.0$ & 241.0 & $212.0-278.5$ & 0.492 & 0.456 \\
\hline Albumin (g/dL) & 4.4 & $4.1-4.5$ & 4.2 & $4.1-4.4$ & 0.153 & 4.3 & $4.2-4.5$ & 4.3 & $4.0-4.4$ & 0.319 & 0.818 \\
\hline Fasting Glucose (ml/dL) & 95.0 & $87.0-103.2$ & 91.0 & $83.2-101.5$ & 0.351 & 90.0 & $84.0-98.0$ & 92.5 & $84.7-98.2$ & 0.410 & 0.126 \\
\hline Total cholesterol (mg/dL) & 218.0 & $194.5-258.5$ & 217.0 & $194.5-254.5$ & 0.758 & 211.0 & $196.0-247.0$ & 208.0 & $183.5-241.5$ & 0.185 & 0.414 \\
\hline $\mathrm{HDL}(\mathrm{mg} / \mathrm{dL})$ & 45.0 & $39.5-50.2$ & 44.0 & $38.0-48.5$ & 0.476 & 46.0 & $41.0-50.0$ & 47.0 & $40.5-54.7$ & 0.905 & 0.689 \\
\hline $\mathrm{LDL}(\mathrm{mg} / \mathrm{dL})$ & 141.0 & $118.7-176.7$ & 146.0 & $122.0-176.0$ & 0.518 & 145.0 & $121.0-169.0$ & 140.5 & $112.0-157.2$ & 0.138 & 0.182 \\
\hline Triglycerides (mg/dL) & 160.0 & $90.7-199.5$ & 146.0 & $98.0-191.5$ & 0.421 & 125.0 & $75.0-165.0$ & 105.0 & $80.0-146.7$ & 0.679 & 0.887 \\
\hline
\end{tabular}

IQR Interquartile range, $R B C$ Reed blood cells, $H D L$ High-density lipoprotein, $L D L$ Low-density lipoprotein

antragroup differences according to Wilcoxon test

${ }^{b}$ Interaction test of a two-way repeated measures ANOVA for ordinal data to verify the significance of differences between fish oil and mineral oil groups 
CRP is an acute-phase serum protein of the pentraxin family produced mainly by hepatocytes and is regulated at the transcriptional level by IL-6. Its plasma concentration increases during inflammatory state [23]. In our study, the placebo group showed an increase in CRP levels, suggestive of an inflammatory response to the tumor, while, in n-3 fatty acids treated-breast cancer patients, the CRP showed a more regulated response. We speculate that $n-3$ fatty acid suplementation might have modulated the inflammatory response to tumor, which in turn could collaborate to a better evolution of the patient during subsequent treatment period. The absence of similar increase in IL- 6 in our study may relate to the differences in the kinetic of their production, in which IL-6 serum levels had already decreased while CRP was still increasing, when tested in the study [23].

These results are consistent with the idea of EPA and DHA acting in the modulation of CRP dependent inflammatory responses. Similar results have been observed in patients with advanced cancer [17, 24]. These results are relevant, given that high levels of CRP have been previously associated with a worse prognosis in breast cancer patients [10] and with the fact that the results could potentially be attributed to n-3 fatty acids supplementation. Our results are also consistent with the potential preventive effect of n-3 fatty acids in breast cancer [12].

According to Calder [25], dietary n-3 fatty acids should be incorporated into leukocyte membrane in order to be an effective immunomodulator. In breast cancer patients, after oral supplementation with $3 \mathrm{~g}$ of polyunsaturated fatty acids n-3 (EPA and DHA) there was a threefold increase in circulating total $n-3$ acids [26]. In the present study, plasma phospholipd fatty acids were used as surrogate markers of compliance to the $n-3$ intervention and after 30 days, the median increase was significant but inferior to those reported by Bagga et al. [26]. These differences in incorporation may relate to the amount of $n-3$ fatty acids supplemented in our study (1.8 g/ day) that could have been insufficient for a higher incorporation. Of note, recent study has indicated that different lipid structures used for EPA and DHA supplementation have similar rates of incorporation into the blood [27].

Low peripheral blood $\mathrm{CD}^{+}$counts $[5,6]$ have been observed even in the early stages of breast cancer patients. Whereas the number of circulating T CD4+ lymphocytes decreased in the placebo group, which is in line with the suppressor substances produced by tumor cells as its immune escape mechanisms, the maintenance of the number of T CD4+ lymphocytes in the $n-3$ fatty acid treated group may have been due to the proliferative effect of fatty acids on lymphocyte functions [2]. In patients of the placebo group, although the number of $\mathrm{TCD}^{+}$lymphocyte did not change, the possibility that the lower number of $\mathrm{TCD}^{+}$lymphocytes might have impaired proliferative capacity of the $\mathrm{TCD}^{+}$cells cannot be ruled out, because helper function of TCD4 ${ }^{+}$ lymphocytes is required to full activation of $\mathrm{TCD}^{+}$cells [28]. As the number of $\mathrm{TCD}^{+}$and $\mathrm{TCD}^{+}$lymphocytes and its ratio remained stable in the fish oil treated group, taken together, the results of our study could suggest a positive effect of fish oil supplement in the adaptive immunity. Surgery is the mainstay of treatment of these patients and this procedure induces substantial immunomodulation, with pro-inflammatory response and leukocytosis [29]. Thus, a balanced adaptive immune response may help prevent postsurgery immunosupression and risks such as tumor dissemination into the circulation [30].

No significant changes were observed in serum proinflammatory cytokines due to the intervention. Similar results in patients with different types of cancer and antineoplastic treatments were reported [14, 31]. Faber et al. [14] supplemented radiotherapy cancer patients with $3.6 \mathrm{~g}$ of $\mathrm{n}-3$ fatty acids for 7 days and changes in the serum proinflamatory cytokines were undetectable to some and not significant to IL-6 and IL-8. Moreover, unlike the results of the present study, they observed a reduction in serum $\mathrm{PGE}_{2}$ levels. Gomez-Candela et al. [31] did not observe reduction of proinflammatory cytokines, but a tendency of increased serum IL-6 after supplementation with EPA and DHA. Nevertheless, it should be considered that cytokines are mainly produced at local levels, so that one can not exclude the possibility that there were modifications in their local levels but that they were not sufficient to modify the systemic serum levels. We were unnable to find previous studies reporting the effects of $n-3$ supplementation on circulating cytokines of breast cancer patients.

Despite the plausibility of antineoplastic effect of $n-3$ fatty acids according to cell culture and animal studies, reports of clinical trials are scarce [32] and the results are inconsistent, one of the reasons being the high variability in the study design. To our knowledge, in the few studies with breast cancer patients, fish oil was studied only as adjuvant to chemotherapy [13, 15, 33]. In our study, the lack of significant findings in relation to proinflammatory cytokines and $\mathrm{PGE}_{2}$ may be in part due to the amount of supplement used or the length of the intervention, that could have been insufficient to be effective. Our intervention have used n-3 dose similar to that used by Bougnoux et al. [13], who reported good tolerance and no side effects. However, according to Mocelim et al. [34], when supplementation is carried out during a short period, higher doses of $\mathrm{n}-3$ fatty acids are required to have an antiinflammatory effect. Also, the use of $\alpha$-tocopherol as antioxidants in fish oil capsules 
may have reduced the effect of n-3 fatty acids, as demonstrated in experimental studies [35]. Other limitation of the study pertains to the discrepancy between the number of invited patients $(n=108)$ and the patients examined $(n=37)$ which affected the study power. Carrying out the study with patients immediately after the diagnosis of such severe disease was challenging for both the research group and patients, and contributed to high refusal and drop out rates. A positive feature of the study was the good compliance to fish oil supplement (92\%), similar to the study by Taylor et al. [24]. As well, the use of mineral oil as placebo had the merit of avoiding the confounding effect of n- 6 fatty acids in the control group. As study participants were treatment naïve, the results may better reflect the patient's metabolic response to the effect of $n-3$ fatty acids.

\section{Conclusions}

In conclusion, the supplementation of newly diagnosed breast cancer patients with $1.8 \mathrm{~g}$ of EPA and DHA for 30 days led to a significant change in the composition of plasma fatty acids, maintained the level of $\mathrm{CD}^{+} \mathrm{T}$ cells and serum levels of CRP, suggestive of a beneficial effect on the immune system. Studies considering the molecular subtypes and clinical staging of the disease would further confirm the results presented.

\section{Abbreviations}

BI-RADS: Breast Imaging-Reporting and Data System; BMI: Body mass index; CRP: C-reactive protein; DHA: Docosahexaenoic acid; EPA: Eicosapentaenoic acid; ER+: Estrogen receptor+; FG: Fish oil group; HER2: Human epidermal growth factor receptor 2; hsCRP: High sensitivity C-reactive protein; IL1B: Interleukin-1B; IL-6: Interleukin-6; IR: Immune response; PA: Phase angle; PBMC: Peripheral blood mononuclear cells; PG: Placebo group;

$\mathrm{PGE}_{2}$ : Prostaglandin $\mathrm{E}_{2}$; PR+: Progesterone receptor+; TNF-a: Tumour necrosis factor alpha

\section{Acknowledgments}

The authors gratefully acknowledge CAPES, Ministry of education and Federal District Research Foundation (FAPDF), Brazil, for scholarship support and research grant, respectively, and Relthy Laboratories Ltd. for the encapsulation of oils used in the study.

\section{Funding}

This work was supported by the Federal District Research Foundation (FAPDF: process number 0193.000.557/2009) and Coordination for the Improvement of Higher Education Personnel (CAPES), Brazil.

\section{Availability of data and materials}

The data set of the current study is available from the corresponding author on request.

\section{Authors' contributions}

The authors' contributions are as follows: EMSP responsible for data acquisition, analysis and manuscript drafting; ACMO, responsible for data acquisition and analysis; MIMJ in general data interpretation and critical review; NP, cell cytometry analyses and interpretation, manuscript review; KGM, immunological data interpretation, manuscript review; EYN statistical analyses; MKl: coordinated the study, data interpretation and manuscript review. All authors read and approved the final manuscript.

\section{Ethics approval and consent to participate}

The study protocol was approved by the Human Research Ethics Committees of the University of Brasilia (Protocol $n^{\circ} 72 / 09$ ) and the Federal District Health Secretariat (Protocol n 383/2011). Informed consent was obtained from each participant before the commencement of the study.

Consent for publication

Not applicable.

\section{Competing interests}

The authors declare that they have no competing interests.

\section{Publisher's Note}

Springer Nature remains neutral with regard to jurisdictional claims in published maps and institutional affiliations.

\section{Author details}

1Post Graduate Program in Human Nutrition, University of Brasília, Brasilia, Federal District 70910-900, Brazil. ${ }^{2}$ Laboratory of Cellular Immunology, Department of Pathology, Faculty of Medicine, University of Brasilia, Brasilia, Federal District 70910-900, Brazil. ${ }^{3}$ Laboratory of Immunology and Inflammation, Department of Cell Biology, Institute of Biology, University of Brasilia, Brasilia, Federal District 70910-900, Brazil. ${ }^{4}$ Department of Statistics, University of Brasilia, Brasilia, Federal District 70910-900, Brazil.

Received: 2 June 2017 Accepted: 10 October 2017

Published online: 23 October 2017

\section{References}

1. Schreiber RD, Old L, Smyth MJ. Cancer immunoediting: integrating immunity's roles in cancer suppression and promotion. Science. 2011;331: 1565-70.

2. Calder PC, Yaqoob P, Thies F, Wallece FA, Miles EA. Fatty acids and lymphocyte functions. Br J Nutr. 2002;87(Suppl 1):31-48.

3. Nicolaou A, Mauro C, Urquhart P, Marelli-Berg F. Polyunsaturated fatty acid-derived lipid mediators and T cell function. Front Immunol. 2014. doi:10.3389/fimmu.2014.00075.

4. McCluskey DR, Roy AD, Abram WP, Martin WM. T lymphocyte subsets in the peripheral blood of patients with benign and malignant breast disease. $\mathrm{Br} J$ Cancer. 1983;47:307-9.

5. Wang ZK, Yang B, Liu H, Hu Y, Yang JL, Wu LL, Zhou ZH, Jiao SC. Regulatory $T$ cells increase in breast cancer and in stage IV breast cancer. Cancer Immunol Immunother. 2012;61:911-6.

6. Campbell MJ, Scott J, Maecker HT, Park JW, Esserman LJ. Immune dysfunction and micrometastases in women with breast cancer. Breast Cancer Res Treat. 2005;91:163-71.

7. Whitford P, Alam SM, George W, Cambell AM. Flow cytometric analysis of tumour-draining lymph nodes in breast cancer patients. Eur J Cancer. 1992; 28:350-6.

8. Fawzy MS, Aly NM, Shalaby SM. El - Sawy WH, Abdul-Maksoud RS. Cyclooxygenase-2 169C>G and 8473T>C gene polymorphisms and prostaglandin E2 level in breast cancer: a case-control study. Gene. 2013; 527:601-5.

9. Goldberg JE, Schertfeger KL. Proinflammatory cytokines in breast cancer: mechanisms of action and potential targets for therapeutics. Curr Drug Targets. 2010;11:1133-46.

10. Sicking I, Edlund K, Wesbuer E, Weyer V, Battista MJ, Lebrecht A, et al. Prognostic influence of pre-operative C-reactive protein in node-negative breast cancer patients. PLoS One. 2014. doi:10.1371/journal.pone.0111306.

11. Valentiz LS, Keshtgar MR, Woodside JV, Leathem AJ, Titcomb A, Perkins KA, et al. Significant changes in dietary intake and supplement use after breast cancer diagnosis in a UK multicentre study. Breast Cancer Res Treat. 2011; 128:473-82

12. Zheng JS, Hu XJ, Zhao YM, Yang J, Li D. Intake of fish and marine n-3 polyunsaturated fatty acids and risk of breast cancer: meta-analysis of data from 21 independent prospective cohort studies. BMJ. 2013;346:f3706.

13. Bougnoux P, Hajjaji N, Ferrasson MN, Giraudeau B, Couet C, Le Floch O. Improving outcome of chemotherapy of metastatic breast cancer by docosahexaenoic acid: a phase II trial. Br J Cancer. 2009;101:1978-85.

14. Faber J, Berkhout M, Fiedler U, Avlar M, Witteman BJ, Vos AP, et al. Rapid EPA and DHA incorporation and reduced PGE2 levels after one week 
intervention with a medical food in cancer patients receiving radiotherapy, a randomized trial. Clin Nutr. 2013;32:338-45.

15. Mansara P, Ketkar M, Deshpande R, Chaudhary A, Shinde K, Kaul-Ghanekar R. Improved antioxidant status by omega-3 fatty acid supplementation in breast cancer patients undergoing chemotherapy: a case series. J Med Case Rep. 2015;9:148.

16. Montovani G, Macciò A, Madeddu C, Gramignano G, Lusso MR, Serpe R, et al. A phase II study with antioxidants, both in the diet and supplemented, pharmaconutritional support, progestagen, and anti-cyclooxygenase-2 showing efficacy and safety in patients with cancer-related anorexia/cachexia and oxidative stress. Cancer Epidemiol Biomark Prev. 2006;15:1030-4.

17. Sánchez-Lara K, Turcott JG, Juárez-Hernández E, Nuñez-Valencia C, Villanueva G, Guevara P, et al. Effects of an oral nutritional supplement containing eicosapentaenoic acid on nutritional and clinical outcomes in patients with advanced non-small cell lung cancer: randomised trial. Clin Nutr. 2014;33:1017-23.

18. World Health Organization. Obesity: preventing and managing the global epidemic. Geneva: WHO; 1998.

19. Barbosa-Silva MC, Barros AJ, Wang J, Heymsfield SB, Pierson RN Jr. Bioelectrical impedance analysis: population reference values for phase angle by age and sex. Am J Clin Nutr. 2005;82:49-52.

20. Folch J, Lees M, Stanley Sloane GH. A simple method for the isolation and purification of total lipides from animal tissues. J Biol Chem. 1957;226:497-509.

21. Christie WW. Method for separation of simple lipid classes. England: Lipid Analyses; 2003. p. 105-35.

22. Brunner $E$, Langer $F$. Nonparametric analysis of ordered categorical data in designs with longitudinal observations and small sample sizes. Biom J. 2000; 42:663-75.

23. Du Clos TW, Mold C. C-reactive protein: an activator of innate immunity and a modulator of adaptative immunity. Immunol Res. 2004;30:261-77.

24. Taylor LA, Pletschen L, Arends J, Unger C, Massing U. Marine phospholipidsa promising new dietary approach to tumor-associated weight loss. Support Care Cancer. 2010;18:159-70.

25. Calder PC. Marine omega-3 fatty acids and inflammatory processes: effects, mechanisms and clinical relevance. Biochim Biophys Acta. 1851;2014:469-84

26. Bagga D, Capone S, Wang HJ, Heber D, Lill M, Chap L, et al. Dietary modulation of omega-3/omega-6 polyunsaturated fatty acid ratios in patients with breast cancer. J Natl Cancer Inst. 1997;89:1123-31.

27. West AL, Burdge GC, Calder PC. Lipid structure does not modify incorporation of EPA and DHA into blood lipids in healthy adults: a randomized-controlled trial. Br J Nutr. 2016;116:788-97.

28. Sallusto F. Heterogeneity of human CD4(+) T cells against microbes. Annu Rev Immunol. 2016;34:317-34.

29. Boomsma MF, Garssen B, Slot E, Berbee M, Berkhof J, Meezenbroek Ede J, et al. Breast cancer surgery-induced immunomodulation. J Surg Oncol. 2010;102:640-8

30. Goldfarb Y, Ben-Eliyahu S. Surgery as a risk factor for breast cancer recurrence and metastasis: mediating mechanisms and clinical prophylactic approaches. Breast Dis. 2007;26:99-114.

31. Gómez-Candela C, Villarino Sanz M, Horrisberger A, Loria Kohen V, Bermejo LM, Zamora Auñón P. Efficacy evaluation of an oral powder supplement enriched with eicosapentaenoic acid in cancer patients. Nutr Hosp. 2011;26:1385-93.

32. Serini S, Ottes Vasconcelos R, Fasano E, Calviello G. How plausible is the use of dietary n-3 PUFA in the adjuvant therapy of cancer? Nutr Res Rev. 2016;29:102-25.

33. Ghoreishi Z, Esfahani A, Djazayeri A, Djalali M, Golestan B, Ayromlou H, et al, Omega-3 fatty acids are protective against paclitaxel-induced peripheral neuropathy: a randomized double-blind placebo controlled trial. BMC Cancer. 2012;12:355

34. Mocellin MC, Camargo CQ, Nunes EA, Fiates GM, Trindade EB. A systematic review and meta-analysis of the $\mathrm{n}-3$ polyunsaturated fatty acids effects on inflammatory markers in colorectal cancer. Clin Nutr. 2016;35:359-69.

35. Xiong A, Yu W, Tiwary R, Sanders BG, Kline K. Distinct roles of different forms of vitamin $E$ in DHA-induced apoptosis in triple-negative breast cancer cells. Mol Nutr Food Res. 2012;56:923-34.

\section{Submit your next manuscript to BioMed Central and we will help you at every step:}

- We accept pre-submission inquiries

- Our selector tool helps you to find the most relevant journal

- We provide round the clock customer support

- Convenient online submission

- Thorough peer review

- Inclusion in PubMed and all major indexing services

- Maximum visibility for your research

Submit your manuscript at www.biomedcentral.com/submit 